\title{
The handling of urinary incontinence in Danish general practices after distribution of guidelines and voiding diary reimbursement: an observational study
} Lars Viktrup*1,2 and Lars Alling Møller ${ }^{3,4}$

Address: ${ }^{1}$ The Research Unit for General Practice, Frederiksborg County, Denmark, ${ }^{2}$ Lilly Research Laboratories, Eli Lilly and Company, Indianapolis, IN, USA, ${ }^{3}$ The Department of Gynecology and Obstetrics, Elsinore Hospital, Frederiksborg County, Denmark and ${ }^{4}$ The Department of Gynecology and Obstetrics, Rigshospitalet, University of Copenhagen, Denmark

Email: Lars Viktrup* - Viktrup_Lars@lilly.com; Lars Alling Møller - Lars.Alling@rh.dk

* Corresponding author

Published: 29 June 2004

BMC Family Practice 2004, 5:13 doi:10.1 186/147|-2296-5-13
Received: 02 March 2004

Accepted: 29 June 2004

This article is available from: http://www.biomedcentral.com/I47/-2296/5//3

(C) 2004 Viktrup and Møller; licensee BioMed Central Ltd. This is an Open Access article: verbatim copying and redistribution of this article are permitted in all media for any purpose, provided this notice is preserved along with the article's original URL.

\begin{abstract}
Background: Though urinary incontinence (UI) is a bothersome condition for the individual patient, the patients tend not to inform their physician about $\mathrm{UI}$ and the physician tend not to ask the patient. Recently different initiatives have been established in Danish general practices to improve the management of Ul. The aim of this study was to identify the handling of urinary incontinence $(\mathrm{UI})$ in Danish general practices after distribution of clinical guidelines and reimbursement for using a UI diary.
\end{abstract}

Methods: In October 200I, a questionnaire was sent to 243 general practitioners (GPs) in Frederiksborg County following distribution of clinical guidelines in July 1999 (UI in general practice) and September $200 \mathrm{I}$ (UI in female, geriatric, or neurological patients). A policy for a small reimbursement to GPs for use of a fluid intake/voiding diary in the assessment of $\mathrm{Ul}$ in general practice was implemented in October 200I. Information concerning monthly reimbursement for using a voiding diary, prescribed drugs (presumably used for treating $\mathrm{UI}$ ), $\mathrm{UI}$ consultations in outpatient clinics, and patient reimbursement for pads was obtained from the National Health Service County Registry.

Results: Of the 132 (54\%) GPs who replied, $87 \%$ had read the guidelines distributed 2 years before, but only $47 \%$ used them daily. The majority (69\%) of the responding GPs had read and appreciated I-3 other UI guidelines distributed before the study took place. Eighty-three percent of the responding GPs sometimes or often actively asked their patients about UI, and $92 \%$ sometimes or often included a voiding diary in the $\mathrm{Ul}$ assessment. The available registry data concerning voiding diary reimbursement, prescribed UI drugs, UI consultations in outpatient clinics, and patient reimbursement for pads were insufficient or too variable to determine significant trends.

Conclusion: GPs management of UI in a Danish county may be reasonable, but low response rate to the questionnaire and insufficient registry data made it difficult to evaluate the impact of different Ul initiatives. 


\section{Background}

Lower urinary tract symptoms, especially urinary incontinence (UI) affect the quality of life in many men and women. UI is defined as the complaint of any involuntary leakage of urine [1]. Stress urinary incontinence (SUI) is defined as the complaint of involuntary leakage on effort or exertion, or on sneezing or coughing, while urge urinary incontinence (UUI) is defined as the complaint of involuntary leakage accompanied by or immediately preceded by urgency [1]. An increasing number of publications have addressed the problem and the World Health Organization has supported the continuing effort of the International Consultation on Incontinence (ICI) to update current knowledge and recommend the optimal management of UI internationally [2]. Since UI affects more than $25 \%$ of all women and about $10 \%$ of all men [3], the general practitioner (GP) plays an important role in the first-line treatment of this common condition that may be treated successfully with simple means in the majority of patients $[4,5]$.

Unfortunately, patients with UI tend not to inform their physician about their symptoms and the physicians tend not to ask their patients if they are having symptoms [6]. Even if the situation seems relevant, only one third of the Danish GPs actually questioned their patients about UI [7]. If UI is discussed, the management is characterized by a high referral rate to specialists [7]. In order to change this situation, several initiatives have been established including the distribution of guidelines for the management of UI and a small reimbursement to GPs to encourage use of a fluid intake/voiding diary in the assessment of UI in general practice [8]. The Danish GPs are paid by the National Health Service with a basic per patient (capitation) payment and additional minor payments for certain other services.

The aim of this study was to evaluate the handling of UI in general practice in a Danish county in relation to distributed clinical UI guidelines and after the introduction of a reimbursement in October 2001 for using a voiding diary in the assessment of UI [8].

\section{Methods}

Frederiksborg county is located in the northern part of Sealand, the main island of Denmark. The 370,555 county inhabitants (per governmental county registry January 1,2002 ) are served by 243 GPs in 128 practices (71 one-doctor, 23 two-doctor, 17 three-doctor, 12 four-doctor, 4 five-doctor, and 1 seven-doctor practices). Each GP in the county had from 632 to 2256 (mean 1451) men, women and children assigned to them.

In July 1999, clinical guidelines for the handling of all patients in general practice were distributed to the Danish
GPs [9]. The guidelines were in line with current ICI recommendations, and were edited by the Danish College of General Practitioners in collaboration with the Danish Colleges of Urology, Gynecology, Geriatry, Neurology, and Rehabilitation. The guidelines were created as professional pamphlets involving algorithms [10], and included a fluid intake/voiding diary that could be downloaded from the Danish College of General Practitioners' website [9].

Other clinical guidelines for the handling of geriatric [11], neurological [12], or female patients [13] were distributed to the 243 GPs in 2001. These guidelines were in line with current ICI recommendations and attached to the September issue of the weekly Journal of the Danish Medical Association, a theme issue concerning UI [14]. The guidelines for lower urinary tract symptoms related to neurological diseases, and the assessment and treatment of UI in geriatric patients, were written in collaboration with the Danish Colleges of General Practitioners, Urology, Gynecology, Geriatrics, Neurology, and Rehabilitation. Guidelines for the assessment and treatment of female UI were written by the Danish College of Obstetricians and Gynecologists and the Danish College of Urologists. These guidelines were designed for obstetricians, gynecologists, and GPs.

A questionnaire (Table 1 see Additional file 1) concerning use of the guidelines and other activities was distributed in October 2001 to the 243 GPs. Three months later, noncompliers received a reminder, but a total of $46 \%$ (111/ 243) did not respond. Initially, a follow-up questionnaire was planned for 1 year after the guidelines were distributed, however, this plan was aborted due to the sub-optimal response rate from the first questionnaire. The questionnaire used was approved by the General Practitioners' Committee for Multi-Centre Studies. It was facevalidated, but not subject to test-retest. The majority of the questions had been used in previously validated questionnaires designed for GPs [7,15]. The questionnaire reflected a status of the UI handling in general practice. Shortly after October 2002, we obtained additional information from the National Health Service County Registry for the first reimbursed year (October 2001 to October 2002) concerning the use of a fluid intake/voiding diary associated with the GP reimbursement.

Information was obtained from the National Health Service County Registry for the dates of October 2000 to October 2002 (the year before and the year after the October 2001 guideline distribution). The information includes: a) prescribed drugs identified by the authors as the most common types used in the treatment of UI in Denmark (daily defined doses of tolterodine, imipramine, or antispasmodics), b) UI-related consultations at the 2 


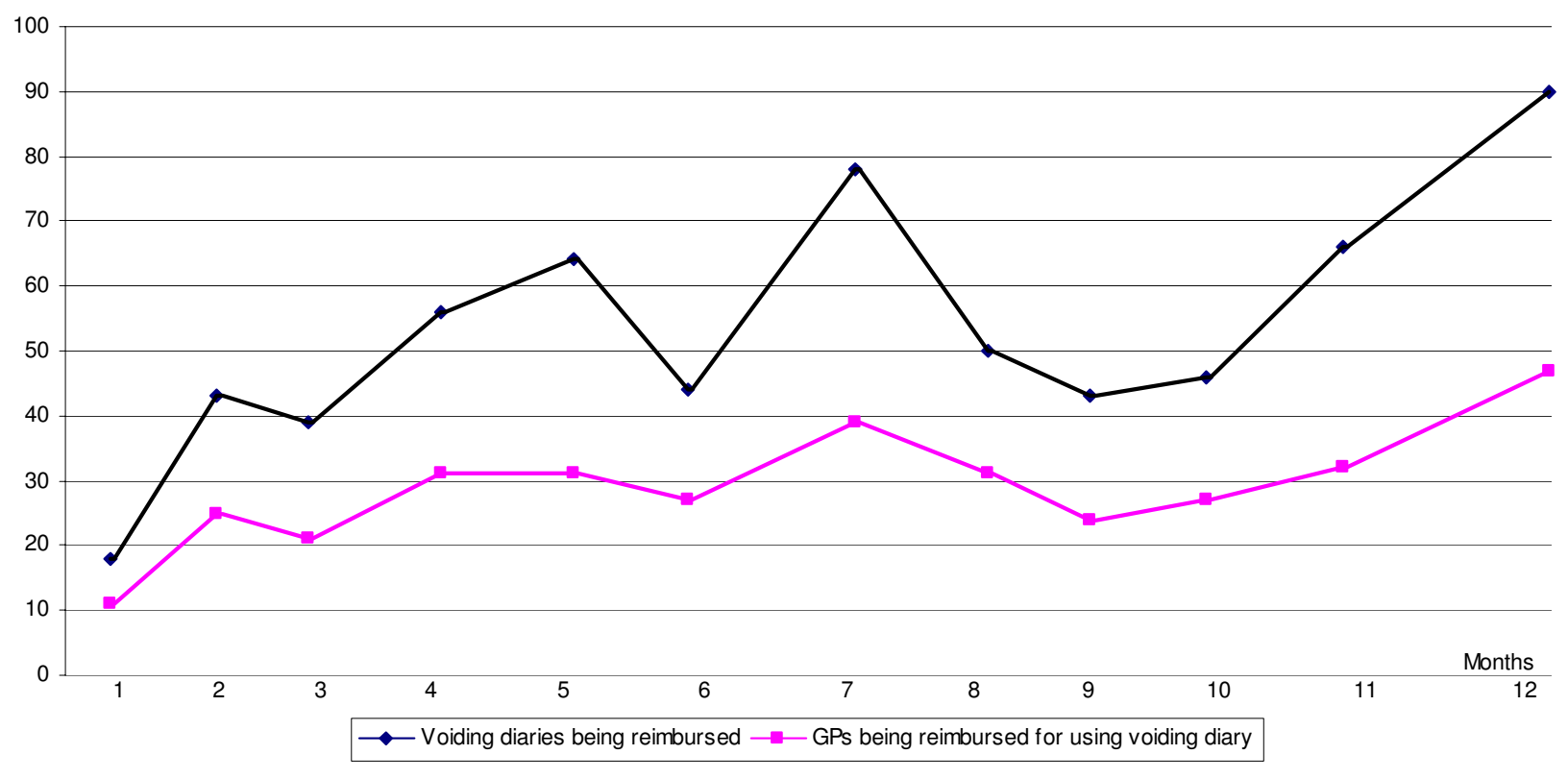

Figure I

Reimbursement to 85 out of 243 gps who used a fluid intake/voiding diary the first 12 months after the introduction of a fee.

gynecological outpatient clinics, the 3 surgical outpatient clinics, and the 1 UI outpatient clinic currently available in the county, c) the municipality reimbursement of UI patients for expenses associated with diapers and pads [16].

\section{Statistics}

The Chi-Square test was used to assess the significance of association. The level of significance was considered $\mathrm{p}<$ 0.05 .

\section{Results \\ Questionnaire}

A total of 54\% (132/243) of the GPs responded (Table 1 see Additional file 1) to the questionnaire. Neither the number of GPs in the individual practices nor the gender (55/91 women, 77/153 men) had any significant impact on the response rate $(\mathrm{p}<0.05)$. Of the responding 132 GPs, 28\% (37) had different suggestions to improve the handling of patients with UI. The majority expressed a need for better communication between the UI specialists and the GPs. While 1 GP was satisfied, 8 of the 37 GPs expressed disappointment with the county's UI outpatient clinic. Some of the non-compliers reflected that replying to surveys on GPs' management of anything guaranteed unfair criticism.
Fluid intake/voiding diary and reimbursement

A total of $35 \%(85 / 243)$ of the county's GPs received reimbursement during the first year after the introduction of payment for using a voiding diary (Figure 1) was established.

\section{Prescriptions}

Tolterodine, emepron, and flavoxate were the only drugs indicated in Denmark for the treatment of UUI during the observation period. No drugs were indicated for the treatment of SUI. Tolterodine was the most used drug during the observation period (Figure 2). Not only did GPs prescribe significantly more tolterodine than hospital physicians, they increased their prescriptions of tolterodine after October 2001 (Figure 2). Emepron and flavoxate were mainly prescribed by GPs, but the prescription rate remained low and did not change. Imipramine is indicated for the treatment of depression and enuresis, but has been used off-label for the treatment of UI. The total prescription rate of imipramine, including all indications, did not change during the observation period.

\section{UI consultations}

Ninety percent of the GPs were aware of the Danish outpatient clinic available especially for UI patients and 55\% of GPs had referred patients (Table 1 see Additional file 1) 


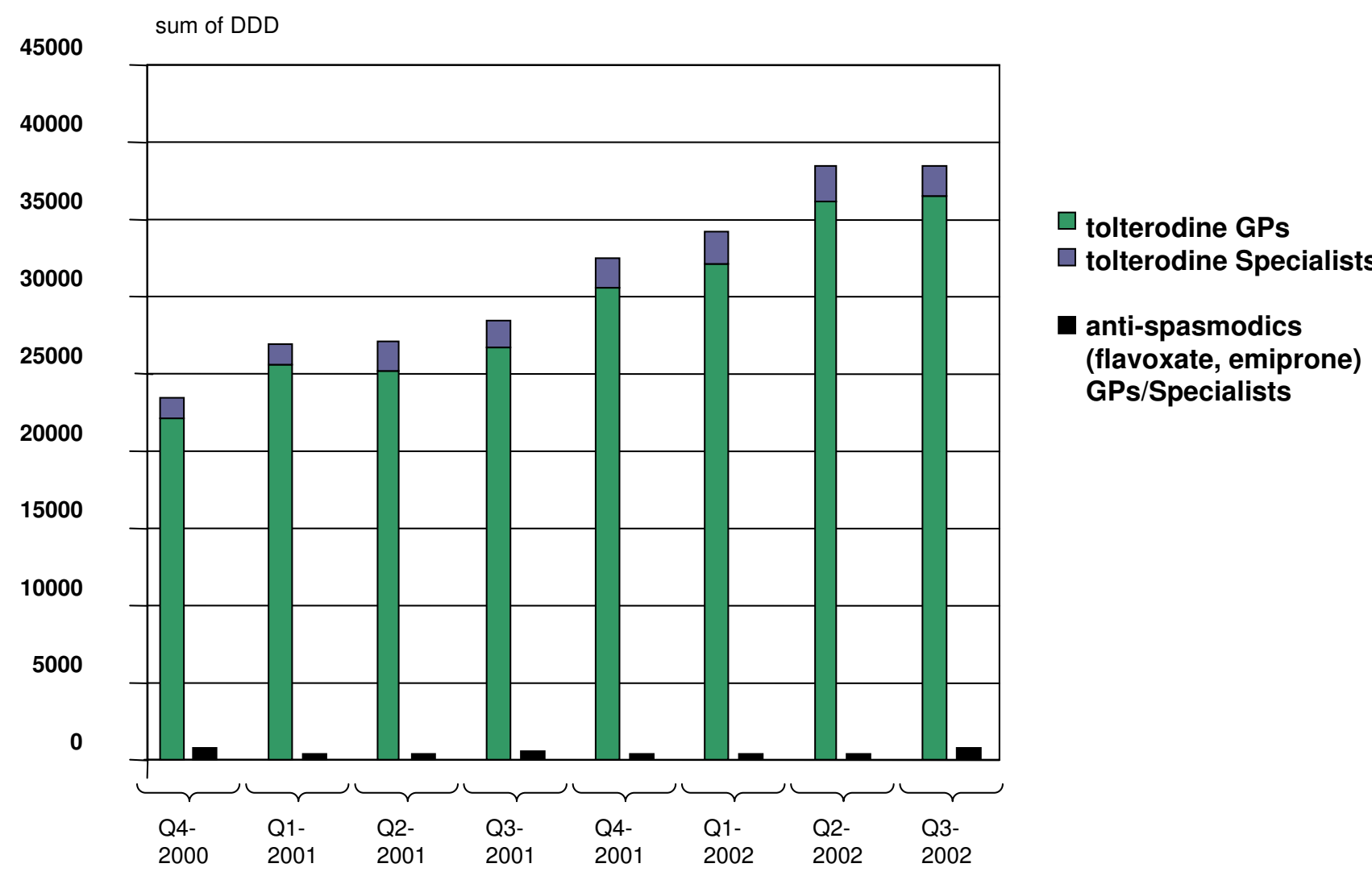

Figure 2

Daily defined doses of agents indicated for uui treatment, october 2000-october 2002

to this clinic. From October 2000-2002 (the year before and the year after the October 2001 guideline distribution), referrals to the 2 gynecological outpatient clinics, 3 surgical outpatient clinics, and 1 UI outpatient clinic in Frederiksborg County fluctuated during the 2-year observation period (Figure 3 ). The UI outpatient clinic was reallocated November 2001 to the main hospital and subsequently closed in August 2002 due to budgetary considerations. Patients with UI seen in the outpatient clinics were all referred, and it was estimated that $85 \%$ of the UI patients seen in the UI outpatient clinic were self-referred [Chief Physician Jens Larsen; personal communication]. None of the consultations in the UI clinic registered a specific UI diagnosis. Significantly $(\mathrm{p}<0.05)$ more UI patients were referred to the outpatient and UI clinics during the third quarter 2001 at the same time the UI guidelines and journal UI theme issue were distributed (Figure 3 ). The total number of patients with UI seen in all 4 clinics was not significantly different 1 year before and 1 year after October 2001, but the referral rate continued to be significantly higher after October 2001 (Figure 3).

\section{Patient reimbursement}

Of the 18 municipalities in the county, only 7 responded to the request concerning reimbursement to patients for use of diapers and pads. Two of the municipalities included incontinence aids for patients with fecal incontinence and another 2 municipalities included patients with UI from nursing homes. From the remaining data, expenses fluctuated during the 2 years of observation.

\section{Discussion}

Clinical guidelines for the management of UI in Danish general practices seem to be received positively by the GPs who answered the questionnaire (Table 1 see Additional file 1). The handling of UI is, however, unclear because of low response rate to the questionnaire and insufficient data available from the county's health registry. The suboptimal compliance to this questionnaire may reflect the heavy workload and, therefore, lack of time to reply to the increasing amount of information GPs receive. However, it is likely the $46 \%$ non-compliers may have a lower level of knowledge and interest in UI and the reported data in 


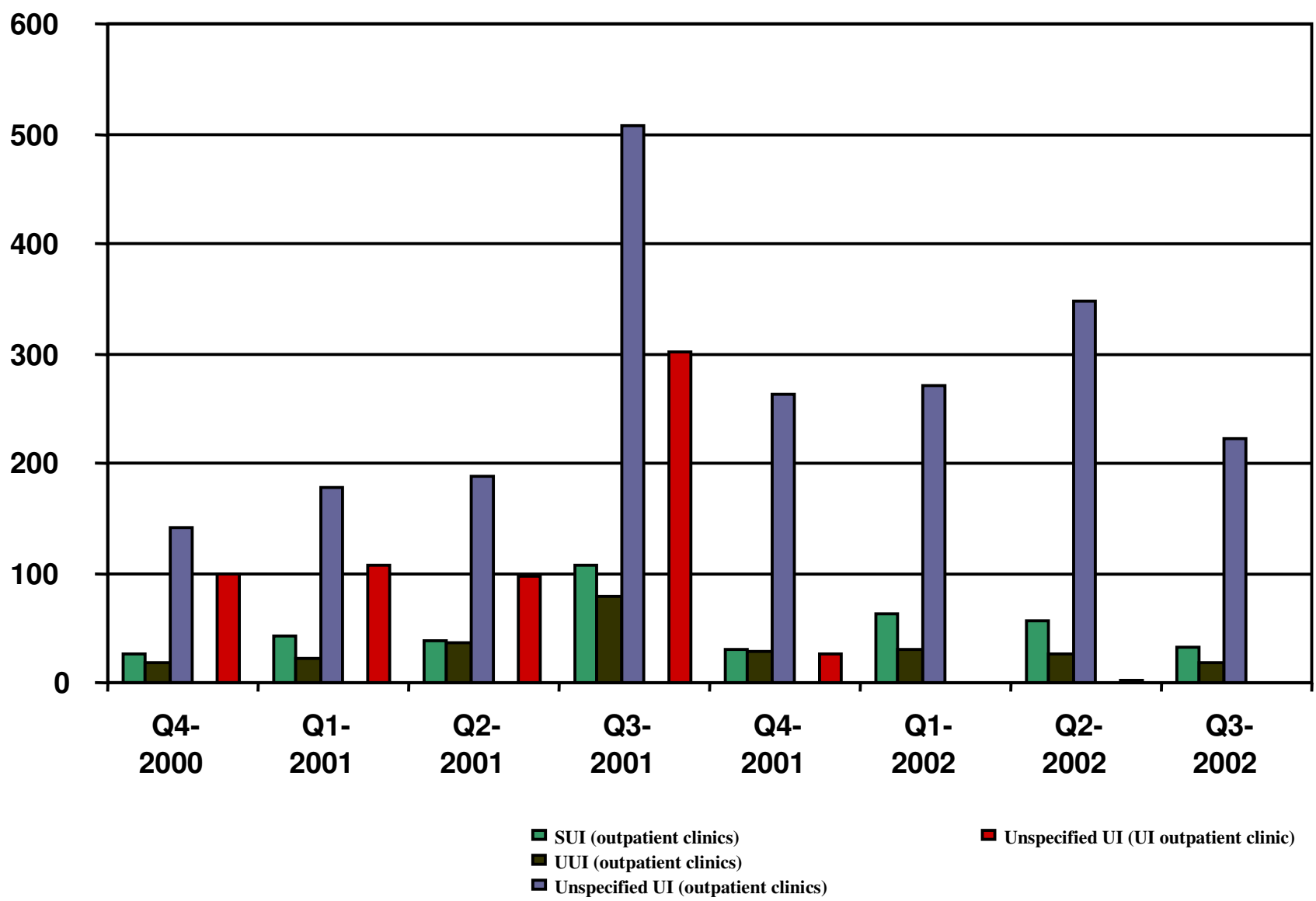

Figure 3

Diagnoses in patients referred to the 5 outpatient clinics and in patients either referred or self-referred to the I ui outpatient clinic, october 2000-october 2002

this study are biased in a positive direction. For those GPs responding to the questionnaire, there is an additional risk of recall bias.

The impact of reimbursing GPs for using a fluid intake/ voiding diary for the management of UI cannot be determined from this study.

\section{Questionnaire}

Of the GPs who answered the questionnaire, managing UI may be better than recently anticipated [7]. Nearly all appreciated the guidelines. The vast majority of the GPs had read the previous and the present guidelines, as well as several of the articles in the UI-themed issue of The Journal of The Danish Medical Association. However, some of the GP's may have paid more attention to the guidelines because they received the questionnaire. The GPs' attitudes to guidelines varied considerably in different studies $[17,18]$. For example, in a recent study from another Danish county, only $44 \%$ of the GPs had read the Danish College of General Practitioners' guidelines for the prevention of ischemic heart disease 6-10 months after they received it [15]. However, $53 \%$ of the GPs who did not read it found guidelines, in general, helpful. The guidelines were used daily by $18 \%$ of the GPs, but guidelines were not available in $32 \%$ of the practices [15].

The questionnaire in the present study was sent: a) 2 years after clinical guidelines for the management of UI were introduced in general practice, b) $2-5$ months after a UIthemed issue including 3 other clinical guidelines concerning UI was published in The Journal of The Danish Medical Association [14], and c) 2-5 months after the announcement of a new reimbursement policy for using a voiding diary. This may be too short a period to significantly change previous procedures in the practices. In comparison, Dutch GPs are accustomed to a high frequency of distributed guidelines created by GP colleges 
Table I: Questionnaire.

The Danish College of General Practitioners distributed July 1999 clinical guidelines for the management of Ul in general practice:

\begin{tabular}{lc}
\hline Have you read it? & Yes:87\%, No: $13 \%$ \\
Do you have it in your practice? & Yes:88\%, No: $12 \%$ \\
Do you use it in your daily work? & Yes:7\%, No:53\% \\
\hline
\end{tabular}

The Journal of The Danish Medical Association [Ugeskr Læger 200I; 163(38)] was a theme issue concerning Ul:

How many of the 9 articles have you read?

Attached to this theme issue [Ugeskr Læger 200I; 163 (38)] was 3 new sets of clinical guidelines:

How many of the clinical guidelines have you read?

Do you think clinical guidelines help you in your daily work?

Is the number of clinical guidelines concerning $\mathrm{Ul}$ appropriate?

Is the number of clinical guidelines concerning other diseases appropriate?

How many of your patients do you know have UI?

How many weekly contacts do you have because of UI?

Do you actively ask any patient about UI?

Do you include a voiding diary in your Ul assesments?
$9-5: 13 \%, 4-1: 63 \%, 0: 25 \%$

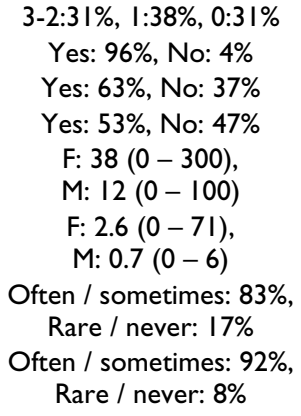

According to \#97 concerning incontinence aids in the Danish Service Law, UI patients may have diapers and pads reimbursed:

How many of your patients have you informed about this option? $45 \%$

Are you aware of the open UI outpatient clinic in the county and have you referred patients?

Do you have any suggestions how the county may better help the incontinent patient?

$90 \%, 55 \%$

$37 / 132$ and revised every 4 years [van der Vort $\mathrm{H}$ presentation at the Danish College of General Practitioners September 22 1998, personal communication]. Though the majority of the Dutch GPs had read many guidelines, 6-12 months after their publication [19], the guidelines did not seem to be permanently implemented [20]. It is a widely accepted fact that patients with identical problems are receiving different care depending on their clinician, hospital, or location [21]. This diversity may be minimized by clinical guidelines that promote interventions of proven benefits and discourage ineffective practices [21]. Clinical guidelines are often inexpensive and widely distributed but difficult to implement [22]. Clinical guidelines should be short, precise, evidence based, and have a clear cut message presented in an inviting layout. They should not demand too many changes to existing routines or resources [20]. In a systematic review from the Cochrane Library, printed educational materials alone do not lead to significant changes in the practice of health care professionals [23]; however, the majority of the studies in this meta-analysis did not reliably assess the cost effectiveness [23]. Sometimes audits, feedback, and conferences may improve the practice of health care professionals [24], but opinion leaders and educational outreach seem to have the highest impact on practice improvements [23].

It has previously been estimated that each Danish GP has at least 75 female and 25 male patients with UI [9]. The GPs in this study were very active in asking their patients about UI, but if the estimate is correct, then they only had knowledge of half of the patients with UI. An explanation could be that patients with mild UI are not bothered enough to reveal their symptoms even though they are asked. In Western Europe, female patients seem to accept UI for an average of 5-7 years before visiting their GP [25]. In 1997, the Gallup International Association conducted an opinion poll in Danish men and women. The poll stated that in 1023 people interviewed UI was one of the most difficult conditions to present to their GP. Only sexual dysfunction and depression ranked higher than incontinence in difficult conditions to discuss with their GP [Professor Gunnar Lose; personal communication]. In a very different health system in Michigan, USA, out of 2830 patients who went to GPs seeking health care for any reason during an 11-week period, 33\% had UI, and of those, $72 \%$ had not told a health care provider [26]. Thus, there is a need for educating patients who are suffering 
from an unneccesary lower quality of life because of UI. Well-written patient recommendations may improve the implementation of professional guidelines in the practices [21].

\section{Fluid intake/voiding diary and reimbursement}

The number of GPs, as well as the number of reimbursements for voiding diaries fluctuated, but slightly increased the first year (Figure 1). The numbers can only be an estimate of the real use of voiding diaries since a diary may have been used without a claim for reimbursement being filed, or the patient with UI may have passed the time of this assessment and already received appropriate treatment. However, it shows at least $65 \%$ of the GPs with an estimated minimum of 100 patients with UI, did not use this very simple recommended assessment tool 1 time in a year. In another Danish study of 795 GPs, their selfreported knowledge and attitude toward assessment and treatment of female UI contributed to the use of a voiding diary increasing from $24 \%$ to $35 \%$ during 1 year (19981999) [7]. The study was performed before there was a reimbursement for the use of a voiding diary.

The Danish GPs are paid by the National Health Service; a health system that seems broadly similar to Norway, UK, and Holland. The other Western European countries differ considerably in the major characteristics of primary care, despite their focus on general practice as the cornerstone of the health system [27]. Practice characteristics such as workload, length of consultation, ordering of tests, and follow-up appointments vary with differences in payment and gatekeeping arrangements [27]. Financial restraint imposed on the GPs in Germany has recently been blamed [28] for discouraging interest in women with UI. Even if a voiding diary reimbursement appears to be a good idea in Denmark, a similar reimbursement plan may have no impact on the management of UI in other countries.

\section{Prescriptions}

The GPs have a significant impact on the amount of drugs prescribed for the treatment of UI in Denmark (Figure 2). The increased tolterodine prescriptions after October 2001 may be a result of both the theme issue of The Journal of the Danish Medical Association, including the guidelines for managing UI, and the associated advertising. Only drugs indicated for the treatment of UUI and not SUI were available during the 2 years of observation. Some of the UUI drugs may have been used off-label to treat SUI, though these drugs have no proven effect in the treatment of SUI [29]. Although no placebo-controlled studies have shown an effect of TCAs in patients with SUI [29], and no quality randomized clinical trials have been conducted in patients with UUI [30], imipramine has been used off-label to treat both SUI and UUI. It was not possible to identify how many of the monthly prescriptions of imipramine were prescribed specifically for UI.

\section{Ul consultations}

A better relationship between GPs and specialists seems desirable since several GPs expressed skeptism, or a need for improvement in the relationship with the UI outpatient clinic. Both the total number of UI patients referred for specialist management, as well as the referral diagnosis (SUI, UUI or others) fluctuated during the observation period for the UI clinic and the other surgical or gynecological outpatient clinics. However, the distributed guidelines and UI-themed issue were timely related to a higher referral rate of UI patients in the third quater 2001; an effect that was maintained the following year. This may indicate increased UI awareness (Figure 3), or it may indicate that patients with UI were constrained to consult their PCP after the reallocation and subsequent termination of the UI clinic. The UI outpatient clinics in Denmark are open to patients with or without referrals.

In 2000, only $2.6 \%$ of the estimated patients in Denmark with UI were admitted to 1 of the 32 gynecological outpatient clinics, 36 surgical outpatient clinics, and 9 UI outpatient clinics [31]. Unfortunately, the assessment and treatment of UI in these clinics varied significantly according to a recent governmental medical evaluation [31].

\section{Patient reimbursement}

Any change in the number of patients being reimbursed for the cost of diapers could not be determined from this study due to insufficient data; however, it seems more patients could benefit from this offer since only $44 \%$ of the GPs had informed their patients about it. The Danish health authorities have the option to reimburse medications or incontinence aids based on the impact of a certain disease. For example, cheaper medication accompanied by physician guidelines significantly increased the Danish GPs' prescription of lipid-lowering drugs [32].

Though the Danish GP already has an intense workload, he or she is facing increasing expectations from hospital specialists who are promoting their niches of expertise. A generalist has to treat each patient based on his or her individual interest, knowledge and practice facility. Practices with multiple GPs have the option to divide areas of diseases between individual physicians, but all practices should ask the patient about UI on a regular basis $[7,33,34]$. In women, this should occur 3 months after childbirth [35], or in addition to the recommended PAP smear every 2-3 years. In view of the GPs' heavy workload and the high prevalence of UI, it would be rational to involve the practice nurses in the management of UI $[5,33]$, possibly by training from other nurses specialized in UI. 


\section{Conclusion}

We conclude that the GPs' management of UI in a Danish county may be resonable, but the impact of clinical guidelines or reimbursement for using a fluid intake/voiding diary for this management is unclear. Using a questionnaire or data from health registries does not seem to provide reliable information. Future surveys need to consider better ways of obtaining controlled data on the GPs' management of this condition.

\section{Declaration of competing interest}

Dr. Viktrup is now a full-time employee of Eli Lilly and Company and holds stock options in the company, however, the study was conducted before Dr. Viktrup was employed by Eli Lilly and Company. Eli Lilly and Company holds no patent or is a manufactur of any of the drugs mentioned in this article.

\section{Authors' contributions}

This manuscript has not been published previously nor concurrently submitted for publication elsewhere. All authors have made substantial contributions to: (1) the concept and design, or analysis and interpretation of data, (2) drafting the article or revising it critically for important intellectual content, and (3) have approved the final version of the manuscript. Dr. LV wrote the protocol, the questionnaire used, and conducted the necessary logistics for obtaining sufficient reply. Additionally, Dr. LV drafted the manuscript and performed the few statistical analyses. Dr. LAM scanned and electronically cleaned the data, interpreted the results, and participated in writing the manuscript.

\section{Additional material}

\section{Additional File 1 \\ danish questionnaire pdf-file \\ Click here for file \\ [http://www.biomedcentral.com/content/supplementary/1471- \\ 2296-5-13-S1.pdf]}

\section{Acknowledgement}

We are thankful to the general practitioners in Frederiksborg County who participated in this study and to the staff of National Health Service County Registry in Frederiksborg County for their support. We are also thankful to Arvid Frank Jørgensen, head of the research unit in General Practice Frederiksborg County, and Tania Miles, publications assistant at Lilly Research Laboratories, for their assistance in the preparation of this manuscript.

\section{References}

I. Abrams P, Cardozo L, Fall M, Griffiths D, Rosier P, Ulmsten U, van Kerrebroeck $P$, Victor $A$, Wein A: The standardisation of terminology of lower urinary tract function: report from the Standardisation Sub-committee of the International Continence Society. Neurourol Urodyn 2002, 2 I (2): I67-78.
2. Abrams Paul and the scientific committee: Foreword. In: Incontinence Second edition. Edited by: Abrams P, Cardozo L, Khoury S, Wein A. Plymouth UK, Health Publication Ltd; 2002:3.

3. Hunskaar S, Burgio K, Diokno, Herzog AR, Hjälmås K, Lapitan MC Epidemiology and natural history of urinary incontinence (UI). In: Incontinence Edited by: Abrams P, Cardozo L, Khoury S, Wein A. Plymouth: Plymbridge; 2002:167-20I.

4. Seim A, Hermstad R, Hundskaar S: Female urinary incontinence: long-term follow-up after treatment in general practice. $\mathrm{Br} J$ Gen Pract 1998, 48: I73।-I734.

5. O'Brien J, Austin M, Sethi P, O'Boyle P: Urinary incontinence: prevalence, need for treatment, and effectiveness of intervention by nurse. BMJ I99|, 303(68 I3): I308-I 2.

6. Kinchen KS, Burgio K, Diokno AC, Fultz NH, Bump R, Obenchain R: Factors associated with women's decisions to seek treatment for urinary incontinence. J Womens Health 2003, I 2(7):687-98.

7. Lose G, Jacobsen AT, Madsen H, Thorsen P, Tibæk S, Johansen B: Alment praktiserende lægers viden om og holdninger til undersøgelse og behandling af kvinder med urininkontinens [General practitioners' knowledge about and attitudes towards assessment and treatment of women with urinary incontinence]. Ugeskr Læger 200I, I 63(38):5।83-5I88.

8. Jensen G, Schøidt AV: Væske/vandladningskema honoreres med ny tillægsydelse. [A new fee for the use of a voiding diary]. Ugeskr Laeger 200I, I63(50):7I I5-7II 7.

9. DSAM: Klinisk Vejledning; Udredning og behandling af urininkontinens i almen praksis. [Danish College of General Practitioners, Clinical Guidelines; Management of urinary incontinence in general practices]. Redistributed as klaringsrapport nr. I, 2000 to all Danish physicians 1999 [http://www.dsam.dk].

10. Jensen G, Walter S: Redaktionelt: Urininkontinens, en vejledning - og hvad så? [Editorial: Urinary incontinence and clinal guidelines,- so what?]. Ugeskr Læger 2000, I 62(7):909.

I I. Klaringsrapport nr. I 0, 200 I. Klinisk Vejledning; Udredning og behandling af urininkontinens hos geriatriske patienter. Clinical Guidelines; Management of urinary incontinence in Geriatric Patients 2001.

12. Klaringsrapport nr. I I, 200 I. Klinisk Vejledning; Vandladningsforstyrrelser ved neurologisk sygdom. Vejledning til neurologer. Clinical Guidelines for Neurologists; Lower Urinary Tract Symptoms and Neurological Disease 200I.

I3. Klaringsrapport nr. I 2, 200 I. Klinisk Vejledning; Udredning og behandling af urininkontinens hos kvinder. Clinical Guidelines; Management of urinary incontinence in Females 200I.

14. Ugeskr Læger 200I, I 63(38):5|43-53 I8.

15. Vægter K, Waldorff FB, Kirkegaard J, Kristensen K: Brug af DSAM's kliniske vejledning om forebyggelse af iskæmisk hjertesygdom I almen praksis [Guidelines for the prevention of ischemic heart disease from The Danish College of Practitioners and its use in General Practice]. Ugeskr Laeger 2000, I 62(44):5959-5982.

16. GPs reimbursement payment \# 2138 for patients with consistent decreased physical abilities where certain accessories significantly improve daily living according to \#97 concerning incontinence aids in the Danish Service Law.

17. Olesen F, Lauritzen T: Do general practitioners want guidelines? Attitudes toward a county-based and a national college-based approach. Scand J Prim Health Care 1997, I 5: |4 |- |45.

18. Feder G: Clinical guidelines in 1994. Let's be careful out there. BMJ 1994, 309:|457-|458.

19. Grol R, Thomas S, Roberts R: Development and implementation of guidelines for family practice: lessons from the Netherlands. J Fam Pract 1995, 40:435-439.

20. Grol R, Dalhuijsen J, Thomas S, in't Veld C, Rutten G, Mokkink H: Attributes of clinical guidelines that influence use of guidelines in general practice: observational study. BMJ 1998 , 3 1 7:858-86|.

21. Woolf SH, Grol R, Hutchinson A, Eccles M, Grimshaw J: Clinical guidelines. Potential benefits, limitations, and harms of clinical guidelines. BM] I999, 3 | 8:527-530.

22. Davis DA, Taylor-Vaisey A: Translating guidelines into practice. Can Med Asssoc J 1997, 157:408-4I6.

23. Freemantle N, Harvey EL, Wolf F, Grimshaw JM, Grilli R, Bero LA Printed educational materials: effects on professional practice and health care outcomes. Cochrane Database Syst Rev 2000:CD000172. 
24. Thomson O'Brien MA, Oxman AD, Davis DA, Haynes RB, Freemantle N, Harvey EL: Audit and feedback: effects on professional practice and health care outcomes. Cochrane Database Syst Rev 2000:CD000259.

25. Toozs-Hobson P, Cardozo L: Family doctor guide to urinary incontinence in women. In: Dorling Kindersley Limited, London 1999.

26. Lagace EA, Hansen W, Hickner JM: Prevalence and severity of urinary incontinence in ambulatory adults: An UPRNet study. J Fam Pract 1993, 36:610-614.

27. Gervas ], Fernandez MP, Starfield $\mathrm{BH}$ : Primary care, financing and gatekeeping in Western Europe. Family Practice 1994, I I:307-3 I7.

28. Weltz-Barth A, Füsgen I, Melchior HJ: Rerun of the $\mathbf{1 9 9 6}$ German urinary incontinence survey: Will doctors ever ask? World J Urol 2000, I 8:436-438.

29. Viktrup L, Bump R: Pharmacological agents used for the treatment of Stress Urinary Incontinence in women. Curr Med Res Opin 2003, I 9(6):485-490.

30. Andersson KE, Appell R, Awad S, Chapple C, Drutz H, Finkbeiner A, Fourcroy J, Haab F, Wein A: Pharmacological treatment of urinary incontinence. In: Incontinence Edited by: Abrams P, Khoury S, Wein A. Plymouth UK: Health Publication Ltd; 2002:48I-5I I.

31. MTV-report: Inkontinensbehandling i Danmark. En statusbeskrivelse over ambulant behandling af patienter med urininkontinens på landets sygehuse. [Patients with urinary incontinence and the management at the out-door clinics in the Danish hospitals; a status report ]. Copenhagen: Danish Center for Evaluation and Health Technology Assessment 200I.

32. Bjerrum L, Larsen J, Kragstrup J: Guidelines accompanied by changes in reimbursement rules. Effects on lipid-lowering drug prescribing. Scand J Prim Health Care 2001, 19:158-162.

33. Dovey S, McNaughton T, Tilyard M, Gurr E, Jolley J, Wilson D: General Practitioners' opinions of continence care training. NZ Med J 1996, 109:340-343.

34. McFall S, Yerkes AM, Bernhard M, Lerud T: Evaluation and treatment of urinary incontinence. Report of a physician survey. Arch Fam Med 1997, 6: I I4- II9.

35. Viktrup L, Lose G: The risk of stress incontinence 5 years after I st delivery. Am J Obstet Gynecol 200I, I 85(I):82-87.

\section{Pre-publication history}

The pre-publication history for this paper can be accessed here:

http://www.biomedcentral.com/1471-2296/5/13/prepub

\section{Publish with Biomed Central and every scientist can read your work free of charge}

"BioMed Central will be the most significant development for disseminating the results of biomedical research in our lifetime. "

Sir Paul Nurse, Cancer Research UK

Your research papers will be:

- available free of charge to the entire biomedical community

- peer reviewed and published immediately upon acceptance

- cited in PubMed and archived on PubMed Central

- yours - you keep the copyright 